Original Research Article

\title{
SDS-PAGE Protein Pattern and Antigenicity Cross Reaction of Human Schistosomes
}

\author{
${ }^{1}$ Nahed A.A. EL-Ossily, ${ }^{1}$ Doaa A. Yones, ${ }^{1}$ Mohamed El-Salahy M.M. Monib, \\ ${ }^{2}$ Ahmed S.A. Hassanin and ${ }^{1}$ Refaat M.A. Khalifa \\ ${ }^{1}$ Department of Medical Parasitology, Faculty of Medicine, Assiut University, Assiut 71526, Egypt \\ ${ }^{2}$ Department of Microbiology and Immunology, Faculty of Medicine, Assiut University, Assiut 71526, Egypt
}

Article history

Received: 26-11-2015

Revised: 28-11-2015

Accepted: 01-02-2016

Corresponding Author:

Doaa A. Yones

Department of Medical

Parasitology, Faculty of

Medicine, Assiut University,

Assiut 71526, Egypt

Email: doaayones@gmail.com

\begin{abstract}
Schistosomiasis is one of the most important neglected tropical diseases. Its control depends on treatment with the available drug praziquantel. No vaccine exists despite the intense search for molecular candidates and adjuvant formulations over the last three decades. The present study aimed to compare the antigenic protein structures of Schistosoma mansoni, S. haematobium, Fasciola. hepatica and Echinococus granulosus hydatid cyst and to find out shared antigens among these species which could be recognized by $S$. mansoni antibodies. Antigenic protein structures were recognized through the use of Sodium Dodecyl Sulfate-Polyacrylamide Gel Electrophoresis (SDS-PAGE) after Coomassie blue staining. Antigenic differences between the detected polypeptides and positive $S$. mansoni serum were performed using Western blotting. The SDS-PAGE profiles of the tested parasites revealed many polypeptides ranging from $15-206 \mathrm{kDa}$. Some of these proteins were shared between all the examined parasites e.g.: $52-47$ and 15-25 kDa. Some ranged from 42-38 $\mathrm{kDa}$ were shared with both examined schistosomes and hydatid cyst fluid. Bands ranged from 58-55 kDa were common in S. mansoni, $S$. haematobium and $F$. hepatica. The protein bands of about $60 \mathrm{kDa}$ crossly reacted with $S$. mansoni serum and detected in all used antigens. The detected immunoreactive proteins from other helminthes could be used to develop potential vaccine against schistosomiasis.
\end{abstract}

Keywords: Platyhelminthes, SDS-PAGE, Western Blotting, Schistosoma Vaccine

\section{Introduction}

Schistosomiasis remains one of the most prevalent diseases in the world especially in the developing countries (King, 2009). It infects between 391 and 600 million people in 74 developing countries in the tropics and sub-tropics and close to 800 million, mostly children, are at risk (King, 2010). The causative agents are several dioecious trematodes, of the family Schistosomatidae, most notably Schistosoma mansoni, S. haematobium and S. japonicum (King, 2009; 2010). $S$. mansoni is the most prevalent species being endemic in 55 countries e.g., Arab peninsula, Egypt, Libya, Sudan, Sub-saharan Africa, Brazil, some Caribbean islands, Suriname and Venzuela (Chitsulo et al., 2000). $S$. haematobium, which is the causative agent of urogenital schistosomiasis, is endemic in 53 countries in Africa and the Middle East; while $S$. japonicum is endemic in China, Indonesia and the Philippines (WHO, 2012). Schistosomiasis control strategies are mainly based on chemotherapy. A single anti-schistosome drug, Praziquantel (PZQ), is readily available. Despite its low cost and self-limiting side-reactions, the drug has only been offered to less than $13 \%$ of the target population (WHO, 2012). Praziquantel is highly effective in treatment of light and moderate infections. However, in areas of high endemicity and transmission and/or intensive PZQ mass administration, PZQ cure rates are almost insignificant (Colley et al., 2014). Many consider that the best long-term strategy to control schistosomiasis is through immunization combined with drug treatment (Bergquist, 2002). An anti- 
schistosomiasis vaccine that induces even a partial reduction in worm burdens could considerably reduce the parasite pathology and limit its transmission (Chitsulo et al., 2004).

An effective vaccine against schistosomiasis is an alternative and desirable tool to help in the disease control; however, the complex schistosome life cycle and the complexity of its interaction with the host immune system turn vaccine development into a difficult task. Neither drug development nor vaccine development is sufficient to ensure the success of schistosomiasis control programs. As a matter of fact, the combination of an effective vaccine together with chemotherapy is the strategy of choice. Many studies demonstrated that without a more sensitive diagnosis test, able to detect individuals with low parasite burden, no control strategy will achieve the desirable result which nowadays is diseases elimination (Fonseca et al., 2013). One of the main reasons hindering the development of a vaccine against schistosomiasis is the entrenched dogma stating protection is dependent on the generation of type 1-immune responses. This belief was based on preponderance of Interferon-gamma (IFN- $\gamma$ ) released by bronchoalveolar leukocytes, total lung tissue and lung-draining lymph nodes in Radiation-Attenuated (RA) cercariae-vaccinated mice (Wynn et al., 1994; Wilson et al., 1996). More importantly, several studies using knockout mice conclusively demonstrated that the optimal protection in the RA vaccine model is dependent on the induction of both type-1 and type-2associated immune responses (Wynn and Hoffmann, 2000; Tallima et al., 2015). It is imperative to use type $2-$, not type 1-inducing cytokines or molecules as adjuvants to the schistosome-derived antigens used for vaccination (El Ridi and Tallima, 2015).

It is not unusual to find common molecules between species of various parasite genera, families, or phyla. The sharing of molecules able to elicit immune responses between different species of various genera is known as antigenic community and it is responsible for antigenic cross-reactivity. The sharing of molecules among organisms is an expected finding because there are many molecules, such as enzymes, hormones, receptors, etc., that have been conserved during evolution. This has special relevance for the identification of molecules with potential for drug or vaccine development effective against different species or genera of organisms (Losada et al., 2005).

The identification of proteins common to $F$. hepatica and $S$. mansoni could provide targets for developing drugs or vaccines that can be simultaneously effective against both organisms. The fatty acid-binding proteins (FABP-Fh15 and Sm14) have been the only $F$. hepatica/S. mansoni-common proteins exploited as a potential dual-vaccine. However, because $F$. hepatica and S. mansoni are parasites with great antigenic complexity, it is expected that they possess common proteins other than FABPs that might contribute to serological cross-reactivity (Vilar et al., 2003).

Experimental co-infection with E. granulosus and $S$. mansoni showed marked reduction in hepatic granuloma size with absence of concentric fibrosis. Thus the effects of helminthes on infections with other pathogens are complex and dependent on many factors such as the helminthes species, co-infecting pathogen, protective and pathological immune mechanisms (Elwakil et al., 2007).

The present study aimed to compare the antigenic protein structures of $S$. mansoni, $S$. haematobium, $F$. hepatica and E. granulosus hydatid cyst and to find out shared antigens among these species which could be recognized by $S$. mansoni antibodies through the use of western blot technique and which could be considered as a base for a vaccine for protection against these parasites.

\section{Materials and Methods}

\section{Antigens Preparation}

\section{S. mansoni and S. haematobium Antigens}

\section{Soluble Adult Worm Antigens (AWA)}

Adult worms of $S$. mansoni and S. haematobium (Egyptian strain) were provided by Schistosoma Biological Supply Program Unit (SBSP), Theodor Bilharz Research Institute (TBRI), Giza, Egypt. They were obtained from experimentally infected mice and golden hamester. They were homogenized, sonicated then centrifuged at $20000 \mathrm{rpm}$ for one hour at $4^{\circ} \mathrm{C}$. Its protein contents were measured and stored at $-20^{\circ} \mathrm{C}$ until used (Deelder et al., 1976).

\section{Soluble Egg Antigen (SEA)}

The eggs of $S$. mansoni and $S$. haematobium were provided by TBRI. They were suspended in $4^{\circ} \mathrm{C}$ Phosphate Buffer Saline (PBS) at a concentration of 100,000 eggs $\mathrm{mL}^{-1}$. The eggs were homogenized on ice, centrifuged at $200 \mathrm{rpm}$ for $20 \mathrm{~min}$. SEA was ultracentrifuged for $90 \mathrm{~min}$ at $100,000 \mathrm{rpm}$ at $4^{\circ} \mathrm{C}$. Its protein contents were measured and stored at $-20^{\circ} \mathrm{C}$ until used (Lewis, 1998).

\section{F. hepatica Antigens}

\section{Total Soluble Extract of Fasciola Adult Worm (TSE)}

Adult Fasciola worms were recovered from the liver of freshly slaughtered sheep at local abattoirs. Worms were washed in $0.01 \mathrm{mM}$ cold PBS, homogenized and 
complemented with Phenylmethylsulfonyl Fluoride (PMSF) one $\mathrm{mM}$ and leupeptine at $0.5 \mu \mathrm{g} \mathrm{mL} \mathrm{m}^{-1}$ (as protease inhibitors). TSE was centrifuged at $12.000 \mathrm{rpm}$ for $30 \mathrm{~min}$ and stored at $-20^{\circ} \mathrm{C}$ after its protein contents estimation, until used. TSE of Fasciola was obtained according to Strauss et al. (1997).

\section{Fasciola Adult Worm Vomit (AWV)}

Fasciola worms were washed in $0.9 \mathrm{M} \mathrm{NaCl}$ at room temperature. They were incubated with fresh cold $0.9 \mathrm{M}$ $\mathrm{NaCl}$ at $4^{\circ} \mathrm{C}$ for $45 \mathrm{~min}$. The worms were again incubated at $37^{\circ} \mathrm{C}$ for $30 \mathrm{~min}$ and the supernatant with evident black intestinal content was collected, centrifuged at $12,000 \mathrm{~g}$ for $30 \mathrm{~min}$ and stored at $-20^{\circ} \mathrm{C}$ until used, after measuring its protein contents (Planchart et al., 2003).

\section{Hydatid Cyst Antigen}

\section{Preparation of Crude Hydatid Fluid (CHF) Antigen}

Hydatid cysts were removed from lungs of freshly slaughtered camels. Its fluid was aspirated and centrifuged at $2000 \mathrm{rpm}$ for $20 \mathrm{~min}$. The supernatant was dialyzed overnight against $0.1 \mathrm{mM}$ PBS at $4{ }^{\circ} \mathrm{C}$, transferred to a sterile tube and stored at $-20^{\circ} \mathrm{C}$ until use, after measuring its protein contents (Nasrieh and Abdel-Hafez, 2004).

\section{The Serum Samples}

Sera were obtained from $S$. mansoni experimentally infected mice provided by TBRI to be used in western blot against the previously prepared antigens. Negative or normal control sera were obtained from non Schistosoma infected mice. All mice were free for other parasites.

\section{Sodium Dodecyl Sulphate Poly-Acrylamide Gel Electrophoresis (SDS-PAGE)}

For separation of proteins, discontinuous SDSPAGE with $12.5 \%$ concentration under denaturated conditions was carried out as described by Laemmli (1970) using a mini gel. One part of antigens were diluted with two parts (v/v) of sample buffer [2\% SDS, $5 \%(\mathrm{v} / \mathrm{v})$ b-mercaptoethanol, $0.1 \%$ bromophenol blue and $0.25 \%(\mathrm{v} / \mathrm{v})$ glycerol in $62.5 \mathrm{mM}$ Tris- $\mathrm{HCl}, \mathrm{pH}$ 6.8 ] and then boiled for three minutes in a water-bath. The solution was mixed and then degassed by attaching the flask to a vacuum for $15 \mathrm{~min}$ and finally poured into the mould as a separating gel (Biogene). The gel was allowed to set and then the stacking gel was poured on top of the running gel with the comb in place. The wells were filled with $30 \mu \mathrm{L}$ antigen extracts. Non-prestained Molecular Weight (MW) standards (wide range, Bio Basic Inc Canada) were incorporated into the control gel lanes to determine the relative molecular weights of the resolved proteins. Electrophoresis was carried out on a vertical gel slab (Bio-Rad mini gel unit ${ }^{2}$, Bio-Rad, USA) in $12 \%$ polyacrylamide gel and 5\% stacking gel, under reducing condition at $150 \mathrm{~V}$ for approximately $1.5 \mathrm{~h}$. The recovered gel was either stained using Coomassie ${ }^{\circledR}$ blue R-250 to visualize protein bands or transferred to Immobilon-p transfer membrane to perform immunobloting.

\section{Western Blotting or Immunoelectroblotting}

Following SDS-PAGE, the antigens were electrophoretically transferred to Immobilon-p transfer membrane (Millipore Corporation, Bedford, USA) for $1.5 \mathrm{~h}$ at $100 \mathrm{~V}$ in a transfer buffer $(0.025 \mathrm{M}$ Trisglycine; $\mathrm{pH} 8.3,20 \% \mathrm{v} / \mathrm{v}$ methanol) using a Mini TransBlot ${ }^{\circledR}$ Transfer Cell (Bio-Rad) to identify antigenic subunits within parasite's antigens by immunoblotting as described by Towbin et al. (1979). The membrane was blocked with 5\% Bovine Serum Albumin (BSA) powder in $0.1 \mathrm{M}$ PBS. The membranes were separately incubated overnight at $4{ }^{\circ} \mathrm{C}$ with serum of Schistosoma infected and non-infected mice, diluted 1:100 and 1:200 in $1 \%(\mathrm{BSA})$ in PBS, 1\% Tween 20. The reactions were developed using alkaline phosphatase-conjugated goat anti-human IgG (H\&L chain) (Sigma), diluted 1:1,000 in $1 \%$ BSA, PBS, $0.005 \mathrm{M}$ Tween 20 and incubated for four hours at room temperature. The transferred antigens were visualised by staining with $3.3^{\prime}, 5,5^{\prime}$ Tetra Methylebenzidine (TMB; Kirkegard and Perry Laboratories, USA). Molecular Weight (MW) estimates were made by comparing the motility of the tested samples with that of the standard protein mixture the standard protein mixture (Amersham pharmacia biotech. USA). Molecular mass of both the SDS-PAGE and western-blot was determined using GelProAnalyzer package (Media Cybernetica; 1993). Both expirements were repeated three times.

\section{Results}

Using SDS-PAGE for protein analysis of the tested antigens, S. mansoni Adult Worm Antigen (AWA), revealed the presence of nine polypeptides. Their MW ranged from 206 to $15 \mathrm{kDa}$. The major protein bands were at MW of $206.4,103.2,68.2,56.6,48.5,39.2$, 31.8, 25.4 and $15.9 \mathrm{kDa}$ (Fig. 1: Lane 1). While $S$. mansoni SEA revealed the presence of seven visible protein bands. Their MW ranged from 74 to $15 \mathrm{kDa}$. The major bands were at MW of 73.9, 47.8, 42.0, 33.6, 33.4, 26.4 and 15.7 kDa (Fig. 1: Lane 2).

Concerning adult $S$. haematobium Soluble Worm Antigen (AWA) revealed eight polypeptides; which 
polypeptide MW ranged from 190 to $16 \mathrm{kDa}$. These bands were corresponding to Molecular Weights (MW) of 186.1, 73.1, 57.4, 50.2, 45.0, 40.0, 25.2 and $16.9 \mathrm{kDa}$ (Fig. 1: Lane 3). At the same time nine polypeptide bands were observed in fractionation of $S$. haematobium SEA. Their MW was ranged from 196 to $15 \mathrm{kDa}$. These bands were corresponding to MW of 195.8, 71.9, 56.4, 50.0, 42.0, 31.7, 31.3, 25.2 and $15.3 \mathrm{kDa}$ (Fig. 1: Lane 4). F. hepatica Total Soluble Extract (TSE) and Adult Worm Vomit (AWV) revealed multiple components via SDS-PAGE. The TSE revealed four major protein fractions with MW of 63.0, $51.7,25.0$ and $14.9 \mathrm{kDa}$ while that of Fasciola AWV antigen revealed six major protein fractions at MW of 90.0, 70.5, 61.5, 55.0, 47.5 and 25.0 kDa (Fig. 1: Lane 5 and Lane 6 respectively).

Fractionation of CHF antigen using SDS-PAGE revealed eleven bands at MW of $80.5,70.0,64.8$, $59.4,47.5,42.0,38.0,34.0,32.8,24.2$ and $17.0 \mathrm{kDa}$ (Fig. 1: Lane 7).

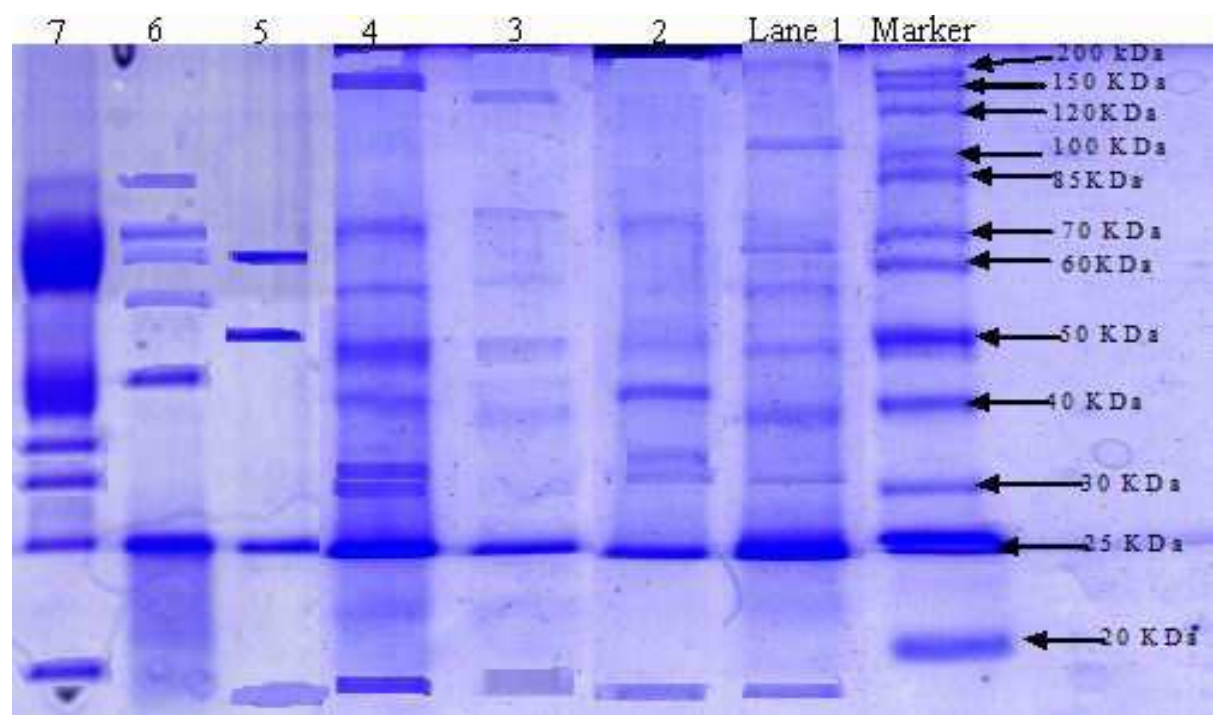

Fig. 1. Polypeptide composition of the tested antigens by SDS-PAGE stained with Commassie brilliant blue, M: Molecular weight marker (M); Lane 1: soluble AWA of S. mansoni; Lane 2: SEA of S. mansoni; Lane 3: Soluble AWA of S. haematobium; Lane 4: SEA of S. heamatobium; Lane 5: F. hepatica TSE; Lane 6: F. hepatica AWV; Lane 7: Hydatid Cyst Fluid (CHF)

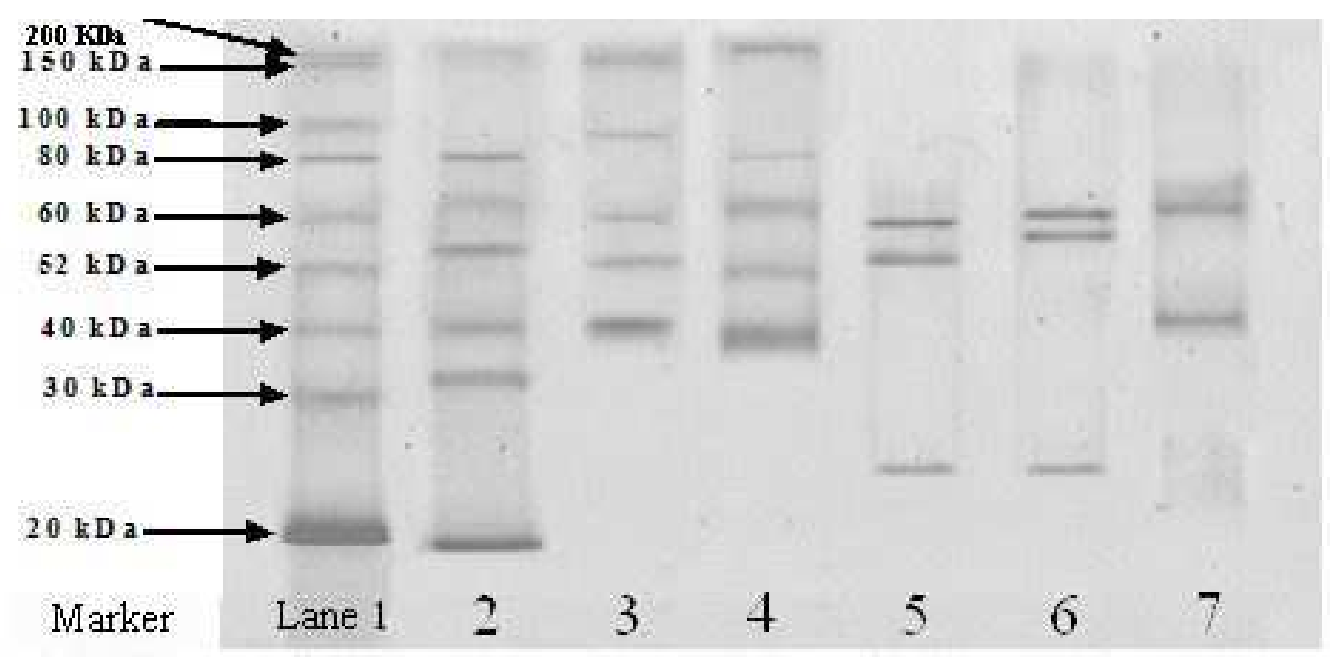

Fig. 2. Immunoblot reaction of the crossly reacted tested antigens using $S$. masoni serum; Lane 1: Protein bands of $S$. mansoni AWA; Lane 2: protein bands of $S$. mansoni SEA; Lane 3: Protein bands of S. haematobium AWA; Lane 4: Protein bands of $S$. haematobium SEA; Lane 5: Protein bands of $F$. hepatica TSE; Lane 6: protein bands of $F$. hepatica AWV; Lane 7: Protein bands of CHF 
Western Blotting (WB) of $S$. mansoni AWA and SEA showed that, $S$. mansoni positive serum recognized the bands with MW of approximately 200, 150, 100, 80, 60, 52, 40, 31 and $20 \mathrm{kDa}$ in AWA (Fig. 2: Lane 1) and 200, 80, 63, 54, 40, 33 and $19 \mathrm{kDa}$ in SEA (Fig. 2: Lane 2). Immunoblot of $S$. haematobium AWA and SEA against $S$. mansoni positive serum showed cross reaction with the bands of approximately 184, 95, 59, 52 and $40 \mathrm{kDa}$ in AWA (Fig. 2: Lane 3) and 195, 79, 63, 50 and $38 \mathrm{kDa}$ in SEA (Fig. 2: Lane 4).

Electrophoretically separated polypeptides from $F$. hepatica TSE and AWV antigens were transferred to nitrocellulose membrane and immunoblotted agaist $S$. mansoni positive serum. From these polypeptides, three polypeptides at MW of 59,52 and 23 reacted crossly with $S$. mansoni positive serum in case of TSE (Fig. 2: Lane 5). While in AWV, polypeptides at MW of 60, 55 and $23 \mathrm{kDa}$ crossly reacted with the serum (Fig. 2: Lane 6). Western blotting of CHF against $S$. mansoni positive serum showed cross reactions at only two polypeptides at MW of 61 and $40 \mathrm{kDa}$ for CHF (Fig. 2: Lane 7). Negative or normal control sera did not show any reaction with the antigens or extracts used in WB.

\section{Discussion}

The current study clarified the antigenic similarity between $S$. haematobium, S. mansoni, F. hepatica and E. granulosus hydatid cyst from the aspect of molecular weight using SDS-PAGE and from the aspect of immune reaction using WB technique against $S$. mansoni positive serum. The examination of these crude extracts, instead of more simplified material, had the advantage of increasing the chance of detecting the most abundant proteins expressed by these parasites (Hamilton et al., 1998) and that could be relevant with respect to the aim of the current study.

In the present study, fractionation of $S$. mansoni AWA revealed nine polypeptide bands ranged from 206.4 to $15.9 \mathrm{KDa}$. While seven visible protein bands were detected on SDS-PAGE analysis of $S$. mansoni SEA with MW from 73.9 to $15.7 \mathrm{kDa}$. These results showed some similarity to that done by Chacon et al. (2002) who revealed nine specific molecules of $S$. mansoni AWA: 155, 122, 97, 90, 50, 36, 31 and 25 $\mathrm{kDa}$. The finding of the current study also coincided with Basyoni and Abd El-Wahab (2013) study who reported seven major protein bands of the fractioned $S$. mansoni AWA with MW of 92, 70, 67, 54, 44, 30 and $20 \mathrm{kDa}$. The findings concerning SEA fractionation were to some extent related to the findings of Lukacs and Boros (1991) who showed that $S$. mansoni SEA was separated into 15 to 22 different protein bands. The protein bands were divided into nine different fractions $(<21$ and $>200 \mathrm{kDa})$. Stadecker et al. (2001) stated that, the best studied and most abundant egg component of $S$. mansoni is the Sm-p40 antigen representing approximately $10 \%$ of SEA. In addition, Soliman et al. (2003) used SDS-PAGE to analyze soluble worm antigens, cercarial antigen preparations and soluble egg antigens of $S$. mansoni and authors reported that $32 \mathrm{kDa}$ was a chief band of these three fractionated antigens.

In the present study; immunoblot of $S$. mansoni AWA and SEA with $S$. mansoni serum revealed intense reaction recognizing most polypeptides bands obtained in SDS-PAGE. Antigenically active components in $S$. mansoni AWA antigen on reaction with homologous serum were nine polypeptides at MW of 200, 150, 100, 80, 60, 52, 40, 31 and $20 \mathrm{kDa}$. While those of $S$. mansoni SEA were at MW of 200 , $80,63,54,40,33$ and $19 \mathrm{kDa}$. Coinciding with these results, when immunobloting tests employed to detect $S$. mansoni AWA antibodies, an immunogenic fraction with a MW of 31-32 kDa (Sm 31/32) was considered to be the most frequently documented fraction. Thus it is considered of high diagnostic importance and could therefore be used as a serologic marker (Valli et al., 1999; Basyoni and Abd ElWahab, 2013). At the same time, Vendrame et al. (2001) reported that when sera of $S$. mansoni infected patients were analyzed by immunobloting against both $S$. mansoni AWA and SEA elucidated an intense reaction identifying the bands of 204, 194, 164, 152, $130,115,92,67,55,50,40,36,31,25$ and $22 \mathrm{kDa}$.

Ludolf et al. (2014) by using two dimensional electrophoresis and WB techniques were able to identify 47 different antigenic proteins in $S$. mansoni AWA and SEA, a slightly larger number when compared to previous $S$. mansoni serological-proteomic studies.

In present study, SDS-PAGE electrophoresis of $S$. haematobium AWA revealed polypeptides of 186.1, $73.1,57.4,50,45.0,40.0,25.2$ and $16.9 \mathrm{kDa}$. While in $S$. haematobium SEA fractionation nine bands were observed with MW of 195.8, 71.9, 56.4, 50.0, 42.0, $31.7,31.3,25.2$ and $15.3 \mathrm{kDa}$. These findings were closely similar to the findings of Hayunga et al. (1981) who observed the bands of MW at 85, 60, 43 and 30 $\mathrm{kDa}$ on fractionation of $S$. haematobium AWA. Also these results somehow came in line with the results obtained by Hillyer and Pacheco (1986) who demonstrated six distinct bands with MW of 131, 76, 74, 55,40 and $25 \mathrm{kDa}$ on analyzing the protein components of $S$. haematobium adult worm antigen preparation. Concerning the bands obtained for S. haematobium SEA were came in line with Gaafar et al. (1993) who revealed seven bands ranged from 84 to $28 \mathrm{kDa}$ namely, 84, 63, 57, 55, 40, 30 and $28 \mathrm{kDa}$. While Mahfouz et al. (2011) detected bands ranged from 106-18.5 kDa.

The findings of current study revealed that many polypepetides of the soluble $S$. haematobium adult 
worm antigen namely $(184,95,59,52$ and $40 \mathrm{kDa})$ and S. haematobium SEA $(195,79,63,50$ and $38 \mathrm{kDa})$ were recognized by $S$. mansoni serum, reflecting that, the two Schistosoma species share common antigens, confirming numerous previous studies. Hayunga et al. (1981) showed that the majority of $S$. haematobium AWA proteins were recognized by $S$. mansoni sera and that, the only $25 \mathrm{kDa}$ was $S$. haematobium specific. Aronstein and Strand (1983) reported that the majority of soluble AWA recognized by sera from $S$. haematobium infected patients were also recognized by sera from $S$. mansoni infected patients.

In the present work, fractionation of $F$. hepatica TSE revealed the presence of four major protein bands at MW of 63.0, 51.7, 25.0 and $14.9 \mathrm{kDa}$ while that of Fasciola AWV antigen revealed the presence of six major protein bands at MW of 90.0, 70.5, 61.5, $55.0,47.5$ and $25.0 \mathrm{kDa}$. These findings somehow agreed to some previous studies that recorded the presence of eight protein bands in $F$. hepatica TSE with molecular weights ranging from $25.5-48 \mathrm{kDa}$ (Allam et al., 2002) and from 62 to $18 \mathrm{kDa}$ (Meshgi et al., 2008). Meanwhile De Almeida et al. (2007) detected seven protein bands for $F$. hepatica TSE with MW of 57, 44-46, 38, 10, 9 and 8 kDa. For the $F$. hepatica AWV, they observed four polypeptide bands which were at MW of 8,12, 15 and $24 \mathrm{kDa}$. On the other hand, Sabry et al. (2010) reported that resolving of TSE antigen showed MW bands at $62,60,58,37,12.5$ and $6.5 \mathrm{kDa}$, while resolving of the AWV antigen showed bands with MW 56, 37, 29 and $12.5 \mathrm{kDa}$.

The current study clarified the cross reactivity of $F$. hepatica TSE and AWV antigen with $S$. mansoni serum by WB technique; the bands recognized by the serum were 59, 52 and $23 \mathrm{kDa}$ for TSE and 60, 55 and $23 \mathrm{kDa}$ for $\mathrm{AWV}$. The results of the present study were in agreement with those of Hayunga et al. (1981) who revealed degree of immunologic identity between $S$. mansoni and $F$. hepatica. They observed that a protein from $F$. hepatica, with an approximate MW of $60.0 \mathrm{kDa}$, reacted with $S$. mansoni infection serum and this antigen might be biochemically similar to the prominent $60.0 \mathrm{kDa} \mathrm{MW}$ peak found in both $S$. mansoni and $S$. haematobium. Cross reaction between $F$. hepatica TSE antigen and patients with schistosomiasis mansoni was recorded at MW of 45 $\mathrm{KDa}$ and $57 \mathrm{KDa}$ by Farghaly et al. (2009) and at MW of 37, 32, 29 and $21 \mathrm{kDa}$ by Sabry et al. (2010). This cross reaction might be due to the fact that, $F$. hepatica and $S$. mansoni have evolved in similar ways to avoid the immune responses of their hosts (McManus and Dalton, 2006).

Maghraby et al. (2009) observed heterologous resistance between $S$. mansoni and F. hepatica. A low molecular weight common component of $14 \mathrm{kDa}$ isolated from $S$. mansoni stimulates a protective response against both $S$. mansoni and $F$. hepatica infections. Such a dual-purpose vaccine, aimed primarily for veterinary use against an economically important disease such as fasciolosis, might represent an attractive route for the development of a vaccine against schisotsomiasis (Hillyer, 2005). In this respect Boukli et al. (2011) used two dimentionalPolyacrylamide Gel Electrophoresis (PAGE) technique and revealed considerable similarity in the proteomic maps of $F$. hepatica and $S$. mansoni with respect to the number of spots detected and their MW. They identified 28 immunoreactive proteins that were common to both adult $F$. hepatica and $S$. mansoni and they suggested that some of the identified proteins could be used to develop vaccines against both fascioliasis and schistosomiasis.

Resolving of CHF antigen by SDS-PAGE revealed bands at $80.5,70.0,64.8,59.4,47.5,42.0$, $38.0,34.0,32.8,24.2$ and $17.0 \mathrm{kDa} \mathrm{MW}$. The data found in this study were somehow in agreement with those obtained in a previous study conducted by Khalifa et al. (2005), they reported that SDS-PAGE of CHF revealed polypeptides of $140,130,116,106$, $97,86,56,48,38,29,24,20,16,12,8 \mathrm{kDa}$. In the same time Saha et al. (2011), detected polypeptides of $72.8,66.5,60.2,41.0,25.1,19.0$ and $8 \mathrm{kDa}$. On the other hand, Tabatabaie et al. (2013), revealed bands with MW ranged from 8 to 150 in which the sharpest bands with MW of $67 \mathrm{kDa}$ on fractionation of CHF and a fewer number of bands with MW of 12, 16 and 24 on fractionation of Ag-B. The two major antigens in hydatid fluid of camel (the lipoprotein antigen-5 and antigen-B) that was detected by Tabatabaie et al. (2013), also were detected in the present work. Antigen-5 consisted of two major subunits of molecular mass 38 and $20 \mathrm{KD}$ and antigen-B involved three subunits; 24, 16 and $8 \mathrm{kDa}$.

In current study, Immunoblotting of CHF against $S$. mansoni serum identified two major discrete antigenic fractions: 61 and $40 \mathrm{kDa}$ in $\mathrm{HCF}$ antigen and no polypeptides were detected in MW bands corresponding to Ag-B. Coinciding with these findings, many studies reported that, the cluster of bands $(35-38 \mathrm{kDa})$ of $\mathrm{CHF}$ crossly reacted with sera from patients with other parasitic infections including schistosomiasis and fascioliasis (Rott et al., 2000; Al-Olayan and Helmy, 2012). The cross reactivity of these polypeptides might be attributed to its phosphorycholine epitope, first described by Shepherd and McManus (1987). Another explanation for the detected cross reactivity was that the chronic parasite diseases produce a discharge of highly immunogenic substances into the host organism, which elicit cross-reactive or non-specific 
immune response, as in case of the schistosomiasis and hydatidosis (Ishida et al., 2003). The finding concerning immunoblotting of Ag-B was fairly similar to previous study conducted by Al-Olayan and Helmy (2012), who observed that, the polypeptides at 24-22, 16 and $8 \mathrm{kDa}$ which corresponding to Ag-B showed 100\% specificity as they did not react with sera from patients with other parasitic diseases. The explanation of the detected cross reactivity in the examined parasites antigens when immunoblotted against $S$. mansoni serum might be due to the fact that, $F$. hepatica and $S$. mansoni had evolved in similar ways to avoid the immune responses of their hosts. Therefore, it was not surprising that several of the common proteins identified between $F$. hepatica and $S$. mansoni antigens as they had biological functions related to immune evasion mechanisms. Another explanation for the cross reactivity among these parasites was that, the chronic parasite diseases produced a discharge of highly immunogenic substances into the host. These substances provoked cross reactive or nonspecific immune response such as in case of the schistosomiasis, fascioliasis and hydatidosis. On the other hand, it was significant to point out that an immunologic fraction with MW of 31-32 kDa was considered to be the most frequently documented fraction in $S$. mansoni AWA and it was specifically reacted with the $S$. mansoni serum.

\section{Conclusion}

Using SDS-PAGE analysis of antigens of $S$. mansoni (AWA, SEA), S. haematobium (AWA, SEA), $F$. hepatica (TSE, AWV) and Hydatid cyst (CHF) revealed many shared proteins between the examined parasites extract. It was noticed that, the polypeptides ranged from $73-68 \mathrm{kDa}$ and that ranged from $42-38 \mathrm{kDa}$ were shared with the AWA, SEA of both examined schistosomes and CHF. Bands ranged from 58-55 kDa were common in S. mansoni AWA, S. haematobium (AWA, SEA) and $F$. hepatica AWV. Bands within the range of 52- 47 and $26-22 \mathrm{kDa}$ were detected in all tested antigens. Bands with MW of $34-31 \mathrm{kDa}$ were observed in S. mansoni (AWA, SEA), S. haematobium SEA and CHF. Bands ranged between 15- $17 \mathrm{kDa}$ were shared with all tested antigens except for $F$. hepatica AWV. Using WB; the protein bands with MW of about $60 \mathrm{kDa}$ crossly reacted with S. mansoni serum and detected in antigens of $S$. mansoni (AWA, SEA), S. haematobium (AWA, SEA), F. hepatica (TSE, AWV) and CHF. These immunoreactive proteins could be used to develop dual vaccine against human schistosomes. Using a more sensitive staining method, e.g., silver staining was recommended to check whether their main bands still can match the bands in western blot. This could help to compare the
$60 \mathrm{kDa}$ band with different method and should highlight this protein in different gels. Also it could show whether the band was only one protein or several proteins with similar molecular weight.

\section{Acknowledgement}

The authors would like to thank Professor Dr. Salma M. Abdel Rahman-Department of Medical Parasitology, Faculty of Medicine, Assiut University- for her help with the SDS-PAGE and Western blot.

\section{Funding Information}

This study was financed by the grant office of Faculty of Medicine, Assiut University, Egypt (Reference code: 1168). The authors, therefore, acknowledge with thanks the Grant Office for technical and financial support.

\section{Author's Contributions}

Nahed A.A. EL-Ossily: Carried out the experiments and data-analysis.

Doaa A. Yones: Data-analysis, manuscript preparation and publication.

Mohamed El-Salahy M.M. Monib and Ahmed S.A. Hassanin and Khalifa M.A. Refaat: Manuscript revision.

\section{Conflicts of Interest}

The authors declare that they have no conflicts of interest.

\section{References}

Allam, A.F., E.S. El-Agamy and M.H. Helmy, 2002. Molecular and immunological characterization of Fasciola species. Br. J. Biomed. Sci., 59: 191-195.

Al-Olayan, E.M. and H. Helmy, 2012. Diagnostic value of different antigenic fractions of hydatid cyst fluid from camel and sheep in Kingdom of Saudi Arabia. J. Saud. Chem. Soc., 16: 203-207. DOI: $10.1016 /$ j.jscs.2011.01.001

Aronstein, W.S. and M. Strand, 1983. Identification of species-specific and gender-specific proteins and glycoproteins of three human schistosomes. J. Parasitol., 69: 1006-1017. DOI: 10.2307/3280853

Basyoni, M.M.A. and A.A. EL-Wahab, 2013. Potential Use of Biomphalaria alexandrina snail antigens for serodiagnosis of schistosomiasis mansoni by immunoblot analysis. Iranian $\mathrm{J}$. Parasitol., 8: 65-72.

Bergquist, N.R., 2002. Schistosomiasis: From risk assessment to control. Trends Parasitol., 18: 309-314. DOI: $10.1016 / \mathrm{S} 1471-4922(02) 02301-2$ 
Boukli, N.M., B. Delgado, M. Ricaurte and A.M. Espino, 2011. Fasciola hepatica and Schistosoma mansoni: Identification of common proteins by comparative proteomic analysis. J. Parasitol., 97: 852-861. DOI: $10.1645 / \mathrm{GE}-2495.1$

Chacon, N., S. Losada, B. Noya, B.A. de Noya and O. Noya, 2002. Antigenic community between Schistosoma mansoni and Biomphalaria glabrata: On the search of candidate antigens for vaccines. Mem. Inst. Oswaldo. Cruz., 97: 99-104. PMID: 12426602

Chitsulo, L., D. Engles, A. Montresor and L. Savioli, 2000. The global status of schistosomiasis and its control. Acta Trop., 77: 41-51. DOI: $10.1016 / \mathrm{S} 0001-706 \mathrm{X}(00) 00122-4$

Chitsulo, L., P. Loverde and D. Engels, 2004. Focus: Schistosomiasis. Nat. Rev. Microbiol., 2: 12-13. DOI: $10.1038 /$ nrmicro801

Colley, D.G., A.L. Bustinduy, W.E. Secor and C.H. King, 2014. Human schistosomiasis. Lancet, 383: 61949-61952.

DOI: 10.1016/S0140-6736(13)61949-2

De Almeida, M.A., M.B. Ferreira, S. Planchart, A. Terashima and V. Maco et al., 2007. Preliminary antigenic characterisation of an adult worm vomit preparation of Fasciola hepatica by infected human sera. Rev. Inst. Med. Trop., 49: 31-35. DOI: 10.1590/S0036-46652007000100006

Deelder, A.M., H.T. Klappe, G.J. Van Den Aardweg and E.H. Van Meerbeke, 1976. Schistosoma mansoni: Demonstration of two circulating antigens in infected hamsters. Exp. Parasitol., 40: 189-197. DOI: 10.1016/0014-4894(76)90081-3

El Ridi, R. and H. Tallima, 2015. Why the radiationattenuated cercarial immunization studies failed to guide the road for an effective schistosomiasis vaccine: A review. J. Adv. Res; 6: 255-267. DOI: $10.1016 /$ j.jare.2014.10.002

Elwakil, H.S., N.M. Ali, R.M. Talaat and W.M. Osman, 2007. Impact of experimental duel infections with Schistosoma mansoni and Echinoccocus granulosus on hepatic histopathology. J. Egypt Soc. Parasitol., 37: 1175-1188. PMID: 18431992

Farghaly, A.M., S.M. Nada, W.A. Emam, M.A. Mattar and S.M. Mohamed et al., 2009. Role of fastELISA and western blot in diagnosis of human fascioliasis using crude adult worm and excretory/secretory Fasciola antigens. Parasitol. Unit. J., 2: 55-65.

Fonseca, C.T., S.C. Oliveira, A.T. Carvalho and R. El Ridi, 2013. Advances in the study of schistosomiasis: The postgenomic era. J. Parasitol. Res., 2013: 849103-849104.

DOI: $10.1155 / 2013 / 849103$
Gaafar, T., S. Ismail, M. Helmy, A. Afifi and N. Guirguis et al., 1993. Identification of Schistosoma haematobium soluble egg antigens that elicit human granuloma formation in vitro. Parasitol. Res., 79: 103-108.

DOI: $10.1007 / \mathrm{BF} 00932254$

Hamilton, J.V., M. Klinkert and M.J. Doenhoff, 1998. Diagnosis of schistosomiasis: Antibody detection, with notes on parasitological and antigen detection methods. Parasitology, 117: 41-45. PMID: 10660931

Hayunga, E.G., W.E. Vannier and R.Y. Chesnut, 1981. Partial Characterization of radiolabeled antigens from adult Schistosoma haematobium. J. Parasitol., 67: 589-599. DOI: $10.2307 / 3280502$

Hillyer, G.V. and E. Pacheco, 1986. Isolation and characterization of Schistosoma haematobium egg antigens. Am. J. Trop. Med. Hyg., 35: 777-785. PMID: 3089037

Hillyer, G.V., 2005. Fasciola antigens as vaccines against fascioliasis and schistosomiasis. J Helminthol., 79: 241-247. DOI: 10.1079/JOH2005304

Ishida, M.M.I., G.R. Elefant, A.W. Ferreira, S.H. Shimizu and A.J. Vaz, 2003. Helminth antigens (Taenia solium, Taenia crassiceps, Toxocara canis, Schistosoma mansoni and Echinococcus granulosus) and cross-reactivities in human infections and immunized animals. Acta Trop., 89: 73-84. DOI: 10.1016/j.actatropica.2003.09.005

Khalifa, R.M., S.M. Abdel-Rahman, M.M. Monib and D.A. Yones, 2005. Characteristics of hydatid cyst of camel strain of Echinococcus granulosus in Assiut. EL-Minia Med. Bull., 16: 202-214.

King, C.H., 2009. Toward the elimination of schistosomiasis. New Engl. J. Med., 360: 106-109. DOI: 10.1056/NEJMp0808041

King, C.H., 2010. Parasites and poverty: The case of schistosomiasis. Acta Trop., 113: 95-104. DOI: 10.1016/j.actatropica.2009.11.012

Laemmli, U.K., 1970. Cleavage of structural proteins during the assembly of the head of bacteriophage T4. Nature, 227: 680-685. DOI: $10.1038 / 227680 \mathrm{a} 0$

Lewis, F.F., 1998. Schistosomiasis: In Current protocols in immunology. In: Supplement 28, Coligan, J.E., A.M. Kruisbeek, D.H. Margulies, E.M. Shevach and W. Strober (Eds.), John Wiley and Sons, Inc., New York, pp: 19.1.1-19.1.28.

Losada, S., N. Chacn, C. Colmenares, H. Bermdez and A. Lorenzo et al., 2005. Schistosoma: Crossreactivity and antigenic community among different species. Exp. Parasitol., 111: 182-190. DOI: 10.1016/j.exppara.2005.07.007 
Ludolf, F., P.R. Patrocinio, R.C. Oliveira, A. Gazzinelli and F.H. Falcone et al., 2014. Serological screening of the Schistosoma mansoni adult worm proteome. Plos Negl. Trop. Dis., 8: e2745-e2745. DOI: 10.1371/journal.pntd.0002745

Lukacs, N.W. and D.L. Boros, 1991. Splenic and granuloma T-lymphocyte responses to fractionated soluble egg antigens of Schistosoma mansoniinfected mice. Infect. Immun., 59: 941-948.

Maghraby, A.S., K.H. Shaker and H.M. Gaber, 2009. Cross-reactivity of Schistosoma mansoni-Fasciola gigantica influenced by Saponins. Z. Natur. C, 64: 288-296. DOI: 10.1515/znc-2009-3-422

Mahfouz, A., N. Mahana, I. Rabee and A. El Amir, 2011. Evaluation of different immunological techniques for diagnosis of schistosomiasis haematobium in Egypt. Life Sci. J., 8: 858-867.

Mcmanus, D.P. and J.P. Dalton, 2006. Vaccines against the zoonotic trematodes Schistosoma japonicum, Fasciola hepatica and Fasciola gigantica. Parasitology, 133: 43-61. DOI: $10.1017 / \mathrm{S} 0031182006001806$

Meshgi, B., A. Eslami and F. Hemmatzadeh, 2008. Determination of somatic and excretorysecretory antigens of Fasciola hepatica and Fasciola gigantica using SDS-PAGE. Iranian J. Vet. Res., 9: 77-80.

Nasrieh, M.A. and S.K. Abdel-Hafez, 2004. Echinococcus granulosus in Jordan: Assessment of various antigenic preparations for use in the serodiagnosis of surgically confirmed cases using enzyme immuno assays and the indirect haemagglutination test. Diagn. Microbiol. Infect. Dis., 48: 117-123.

DOI: 10.1016/j.diagmicrobio.2003.09.018

Planchart, S., R.N. Incani, D. Ballen, C. Matos and I. Cesari, 2003. Preliminary biochemical characterization of a Schistosoma mansoni Adult Worm Vomit (AWV) preparation and immunological specificity of a mouse anti-AWV monoclonal antibody. Proceedings of the 9th International Symposium on Schistosomiasis Salvador, Nov. 2-5, BA, Brazil.

Rott, M.B., V. Fernandez, S. Farias, J. Ceni and H.B. Ferreira et al., 2000. Comparative analysis of two different subunits of antigen B from Echinococcus granulosus: Gene sequences, expression in Escherichia coli and serological evaluation. Acta Trop., 75: 331-340. DOI: $10.1016 / \mathrm{S} 0001-706 \mathrm{X}(00) 00069-3$

Sabry, N.M., D.M. Abdel-Hameed and A.M. EL Ashkar, 2010. Identification and evaluation of antigentic epitopes of total soluble extract and adult worm vomit for immunodiagnosis of human fascioliasis. Parasitol. Unit. J., 3: 55-64.
Saha, B., S. Batabyal and S. Chattopadhyay, 2011. Purification and immunobiochemical characterization of sheep hydatid cyst fluid antigen. Biotechnol. Bioinf. Bioeng., 1: 265-268.

Shepherd, J.C. and D.P. Mcmanus, 1987. Specific and cross-reactive antigens of Echinococcus granulosus hydatid cyst fluid. Mol. Biochem. Parasitol., 25: 143-154. DOI: $10.1016 / 0166-6851(87) 90003-X$

Soliman, K., S. Abou-El Dobal and N. Marei, 2003. Effect of carnosine administration on the immune re-sponse of rabbit to Schistosoma mansoni antigens. J. Egypt. Soc. Parasitol., 33: 663-678.

Stadecker, M.J., H.J. Hernandez and H. Asahi, 2001. The identification and characterization of new immunogenic egg components: Implications for evaluation and control of the immunopathogenic $\mathrm{T}$ cell response in Schistosomiasis. Mem. Inst. Oswaldo. Cruz., 96: 29-33. DOI: $10.1590 / \mathrm{S} 0074-02762001000900004$

Strauss, W., R. Angles, J.G. Esteban and S. Mas-Coma, 1997. Human fascioliasis in Bolivia: Serological surveys in Los Andes province of the department of La Paz. Res. Rev. Parasit., 57: 109-113.

Tabatabaie, F., L. Akhlaghi, M. Noori and F. Maleki, 2013. Preparation and purification of antigens of hydatid cyst fluid by serologic diagnosis. Biol. Res., 4: 236-241.

Tallima, H., P.D. John and R. El Ridi, 2015. Induction of protective immune responses against Schistosomiasis haematobium in hamsters and mice using cysteine peptidase-based vaccine. Front. Immunol., 6: 130-130. DOI: 10.3389/fimmu.2015.00130

Towbin, H., T. Staehilin and J. Gordon, 1979. Electrophoretic transfer of proteins from polyacrylamide gels to nitrocellulose sheets: Procedure and some applications. Proc. Nat. Acad. Sci. USA, 76: 4350-4354. DOI: $10.1073 /$ pnas.76.9.4350

Valli, L.C.P., H.R. Kanamura, R.M. Da Silva, R. Ribeiro-Rodrigues and R. Dietze, 1999. Schistosomiasis mansoni: Immunoblot analysis to diagnose and differentiate recent and chronic infection. Am. J. Trop. Med. Hyg., 61: 302-307.

Vendrame, C.M.V., M.D.T. Carvalho, C.R.F. Yamamoto, M.C. Nakhle and S.A. Carvalho et al., 2001. Evaluation of anti-Schistosoma mansoni igg antibodies in patients with chronic schistosomiasis mansoni before and after specific treatment. Rev. Inst. Med. Trop. S. Paulo., 43: 153-159. DOI: $10.1590 / \mathrm{S} 0036-46652001000300007$

Vilar, M.M., F. Barrientos, M. Almeida, N. Thaumaturgo and A. Simpson et al., 2003. An experimental bivalent peptide vaccine against schistosomiasis and fascioliasis. Vaccine, 22: 137-144. DOI: 10.1016/S0264-410X(03)00300-1 
Wilson, R.A., P.S. Coulson, C. Betts, M.A. Dowling and L.E. Smythies, 1996. Impaired immunity and altered pulmonary responses in mice with a disrupted interferon-gamma receptor gene exposed to the irradiated Schistosoma mansoni vaccine. Immunology, 87: 275-282.

DOI: $10.1046 / \mathrm{j} .1365-2567.1996 .465550 . \mathrm{x}$

WHO, 2012. Schistosomiasis: Population requiring preventive chemotherapy and number of people treated in 2010. Wkly Epidemiolol. Rec., 87: 37-44.
Wynn, T.A., I.P. Oswald, I.A. Eltoum, P. Caspar and C.J. Lowenstein et al., 1994. Elevated expression of Th1 cytokines and nitric oxide synthase in the lungs of vaccinated mice after challenge infection with Schistosoma mansoni. J. Immunol., 153: 5200-5209.

Wynn, T.A. and K.F. Hoffmann, 2000. Defining a schistosomiasis vaccination strategy-is it really Th1 versus Th2? Trends Parasitol., 16: 497-501. DOI: $10.1016 / \mathrm{S} 0169-4758(00) 01788-9$ 